\title{
複錯塩, $\left[\mathrm{Co}\left(\mathrm{NH}_{3}\right)_{6}\right]\left[\mathrm{Ln}\left(\mathrm{CO}_{3}\right)_{3}\right] \cdot \boldsymbol{n} \mathrm{H}_{2} \mathrm{O}(\mathrm{Ln}=\mathrm{La}, \mathrm{Sm}, \mathrm{Gd}, \mathrm{Ho})$ の赤外スペクトルと熱分解
}

\author{
（1984 年 9 月 8 日 受 理） \\ 坂本 政臣
}

\section{1 腥言}

希土類金属(III)イオンは過鄱の炭酸イオンあるいは硫酸イオン の存在で錯陰イオンを形成し，それら錯陰イオンがーキサフンミ ンコバルト(III)錯陽イオンとの複錯塩として固定できることが報 告されている(1)るね。また，既報4)ではランタン(II)のスルファト錯 陰イオンがペンタアンミンアクアコバルト（III)あるいはテトラフ ンミンジフクアコバルト（III)錯陽イオンによっても固定できるこ とを見いだし，それら複錯塩のIR スペクトルおよび熱分解につ いて報告した。

本報では $\left[\mathrm{Co}\left(\mathrm{NH}_{3}\right)_{6}\right]\left[\mathrm{La}\left(\mathrm{CO}_{3}\right)_{3}\right] \cdot \mathrm{H}_{2} \mathrm{O}[1],\left[\mathrm{Co}\left(\mathrm{NH}_{8}\right)_{6}\right][\mathrm{Sm}$ ・ $\left.\left(\mathrm{CO}_{8}\right)_{3}\right] \cdot 5 \mathrm{H}_{2} \mathrm{O}[2],\left[\mathrm{Co}\left(\mathrm{NH}_{3}\right)_{6}\right]\left[\mathrm{Gd}\left(\mathrm{CO}_{3}\right)_{3}\right] \cdot 5 \mathrm{H}_{2} \mathrm{O}[3]$ およ $\left[\mathrm{Co}\left(\mathrm{NH}_{8}\right)_{6}\right]\left[\mathrm{Ho}\left(\mathrm{CO}_{3}\right)_{3}\right] \cdot 4 \mathrm{H}_{2} \mathrm{O}[4]$ の 4 種類の複錹塩の IR ス ヘクトル扰よび熱分解について検討し，水の脱離反応の活性化工 ネルギーを求めた。

\section{2 実 験}

\section{1 希土類金属(III)塩化物溶液}

市肘の酸化物をそれぞれ湲塩酸に溶解濃縮ののち, 約 $0.1 \mathrm{~mol}$ ・ $\mathrm{dm}^{-8}$ としたものを貯蔵溶液とした。

\section{2 複錯塩の合成}

2.2.1 $\left[\mathrm{Co}\left(\mathrm{NH}_{3}\right)_{8}\right]\left[\mathrm{La}\left(\mathrm{CO}_{3}\right)_{3}\right] \cdot \mathrm{H}_{2} \mathrm{O}[1]:$ ランタンの貯蔵溶 液 $10 \mathrm{ml}$ にアンモ二ア水を加えて水酸化物を沈殿させる。上澄み 液を除き，炭酸アンモニウム $9.6 \mathrm{~g}$ と炭酸カリウム $14 \mathrm{~g}$ を加え て沈殿を溶解させたのち，液量を水で約 $60 \mathrm{~m} l$ にする。その溶液 にヘキサアンミンコバルト（III)塩化物 $1.4 \mathrm{~g}$ をかきまぜながら溶 解させ, 放置すると淡黄色, 針状の結晶が析出する。汇過後, 水, エタノールおよびェーテルの順に洗浄し，風乾した。

2.2.2 $\left[\mathrm{Co}\left(\mathrm{NH}_{3}\right)_{6}\right]\left[\mathrm{Sm}\left(\mathrm{CO}_{3}\right)_{3}\right] \cdot 5 \mathrm{H}_{2} \mathrm{O}[1],\left[\mathrm{Co}\left(\mathrm{NH}_{3}\right)_{6}\right][\mathrm{Gd}$. $\left.\left(\mathrm{CO}_{3}\right)_{3}\right] \cdot 5 \mathrm{H}_{2} \mathrm{O}[3]$ およひ $\left[\mathrm{Co}\left(\mathrm{NH}_{3}\right)_{6}\right]\left[\mathrm{Ho}\left(\mathrm{CO}_{3}\right)_{3}\right] \cdot 4 \mathrm{H}_{2} \mathrm{O}[4]:$ 斉藤らの方法引にしたがって合成し，汇過後，水，エタノール拉 よびェーテルの順に洗浄し，風乾した。得られた結晶はいずれも 淡黄色，針状である。

2.2.3 組成分析：コバルト，希土類金属およびアンモニアの

愛媛大学工学部工業化学科, 790 松山市文京町

1) V. A. Golovnya, L. A. Pospelova, Zh. Neorg. Khim., 3, 2253(1958).

2) A.Saito, K. Ueno, J. Inorg. Nucl. Chem., 41, 503 (1979).

3) A. Saito, K. Ueno, ibid., 41, 507(1979).

4) M. Sakamoto, Polyhedron, 3, 451(1984).
分析は試料を約 $1.5 \mathrm{~mol} \cdot \mathrm{dm}^{-3}$ 塩酸に溶解して既報 ${ }^{4)}$ と同様な方 法で行なった。炭酸イオンは試料を約 $2 \mathrm{~mol} ・ \mathrm{dm}^{-3}$ 硫酸に溶解, 加熱することによって二酸化炭素の発生を完全にし，窒素気流と ともに濃硫酸に通したのち, 粒状水酸化ナトリウムに吸収させ, その重量変化から定量した。水の量は全量から他の成分の量を差 し引いて求めた。

\section{3 測 定}

赤外スペクトルは $\mathrm{KBr}$ 錠剤法で测定した。 TG 曲線は 80〜 300 メッシュの試料約 $5 \mathrm{mg}$ を静止大気中, 約 $0.7 \sim 10.5^{\circ} \mathrm{C} /$ $\min ^{-1}$ の昇温速度で加熱し，Cahn 2000 電気てんびんにより測定 した。粉末 X線回折スペクトルは日本電子製 X線回折装置により 測定した。

\section{3 結果および考察}

得られた複錯塩の分析結果を表 1 に示す。ランタン（正）の複錯 塩については斉藤らによって一水和物と五水和物のものが報告さ れているが3), 本法によって得られたものは一水和物であった。

3.1 粉末 $\mathrm{X}$ 線回折パターン

図1に示すよらに，〔2〕，〔3〕および〔4〕はよく似ている が，〔1]はかなり異なったパターンを与える。

\section{2 赤外吸収スペクトル}

カルボナト基に基づくスペクトルデータを表 2 に示す。 1333 [1], 1324[2], 1323[3]および $1317 \mathrm{~cm}^{-1}$ [4]の吸収は $\delta_{\mathrm{s}}$ $\left(\mathrm{NH}_{3}\right)$ によるものと思われる5)。これら複錯塩では遊離の炭酸 イオン, 方解石, アラレ石, $\left[\mathrm{Co}\left(\mathrm{NH}_{3}\right)_{5} \mathrm{CO}_{3}\right] \mathrm{Br}$ および $[\mathrm{Co}$. $\left.\left(\mathrm{NH}_{3}\right)_{4} \mathrm{CO}_{3}\right] \mathrm{Cl}$ など6) に比較してカルボナト配位子による吸収带 の分裂がかなり複雑である。また，〔2〕，〔3〕拉よび〔4〕では $\nu_{3}$ に基づく吸収が $1500 \mathrm{~cm}^{-1}$ 以上に現われるが〔1〕ではみら れない。このことはランタニド収縮のために，サマリウム，ガド リニウム怙よびホルミウムとカルボナト配位子との結合がラン タンの場合に比較して大きくなることにも起因していると思われ る。しかしながら，ン に基づく吸収が $\left[\mathrm{Co}\left(\mathrm{NH}_{3}\right)_{4} \mathrm{CO}_{3}\right] \mathrm{Cl}$ で は 1592 および $1255 \mathrm{~cm}^{-1} k^{6)}$, 従来法により合成した [Co・ $\left.\left(\mathrm{NH}_{3}\right)_{6}\right]\left[\mathrm{Co}\left(\mathrm{CO}_{3}\right)_{3}\right]$ では 1583 および $1280 \mathrm{~cm}^{-1}$ に钼湘され， 分裂幅も $300 \mathrm{~cm}^{-1}$ 以上であり，〔1]〜[4]の分裂幅に比較して

5) K. Nakamoto, "Infrared Spectra of Inorganic and Coordination Compounds", John Wiley \& Sons, Inc., New York (1963) p. 151.

6) K. Nakamoto, J. Fujita, S. Tanaka, M. Kobayashi, J. Am. Chem. Soc., 79, 4904(1957) and the references cited therein. 
Table 1 Analytical results

Complex

\begin{tabular}{|c|c|c|c|c|c|}
\hline$[1]\left\{\begin{array}{l}\text { Found } \\
\text { Calcd.a) }\end{array}\right.$ & $\begin{array}{c}11.64 \pm 0.08 \\
11.83\end{array}$ & $\begin{array}{c}27.53 \pm 0.45 \\
27.89\end{array}$ & $\begin{array}{c}20.09 \pm 0.18 \\
20.52\end{array}$ & $\begin{array}{c}36.18 \pm 0.16 \\
36.15\end{array}$ & $\begin{array}{c}4.56 \pm 0.82 \\
3.62\end{array}$ \\
\hline 2] $\left\{\begin{array}{l}\text { Found } \\
\text { Calcd. }\end{array}\right.$ & $\begin{array}{c}10.26 \pm 0.03 \\
10.13\end{array}$ & $\begin{array}{c}26.17 \pm 0.53 \\
25.85\end{array}$ & $\begin{array}{c}17.70 \pm 0.10 \\
17.57\end{array}$ & $\begin{array}{c}31.35 \pm 0.64 \\
30.95\end{array}$ & $\begin{array}{c}14.52 \pm 0.84 \\
15.49\end{array}$ \\
\hline$[3]\left\{\begin{array}{l}\text { Found } \\
\text { Calcd.c }\end{array}\right.$ & $\begin{array}{c}10.09 \pm 0.08 \\
10.01\end{array}$ & $\begin{array}{c}26.68 \pm 0.09 \\
26.72\end{array}$ & $\begin{array}{c}17.39 \pm 0.05 \\
17.36\end{array}$ & $\begin{array}{c}30.30 \pm 0.47 \\
30.59\end{array}$ & $\begin{array}{c}15.54 \pm 0.49 \\
15.31\end{array}$ \\
\hline$[4]\left\{\begin{array}{l}\text { Found } \\
\text { Calcd.d) }\end{array}\right.$ & $\begin{array}{c}10.18 \pm 0.04 \\
10.19\end{array}$ & $\begin{array}{c}28.82 \pm 0.34 \\
28.53\end{array}$ & $\begin{array}{c}17.50 \pm 0.09 \\
17.67\end{array}$ & $\begin{array}{c}30.90 \pm 0.49 \\
31.14\end{array}$ & $\begin{array}{c}12.60 \pm 0.60 \\
12.46\end{array}$ \\
\hline
\end{tabular}

a) Values for $\left[\mathrm{Co}\left(\mathrm{NH}_{3}\right)_{6}\right]\left[\mathrm{La}\left(\mathrm{CO}_{3}\right)_{3}\right] \cdot \mathrm{H}_{2} \mathrm{O}$.

b) Values for $\left[\mathrm{Co}\left(\mathrm{NH}_{3}\right)_{6}\right]\left[\mathrm{S} \cdot \mathrm{m}\left(\mathrm{CO}_{3}\right)_{3}\right] \cdot 5 \mathrm{H}_{2} \mathrm{O}$.

c) Values for $\left[\mathrm{Co}\left(\mathrm{NH}_{3}\right)_{6}\right]\left[\mathrm{Gd}\left(\mathrm{CO}_{3}\right)_{3}\right] \cdot 5 \mathrm{H}_{2} \mathrm{O}$.

d) Values for $\left[\mathrm{Co}\left(\mathrm{NH}_{3}\right)_{6}\right]\left[\mathrm{Ho}\left(\mathrm{CO}_{3}\right)_{3}\right] \cdot 4 \mathrm{H}_{2} \mathrm{O}$.

Table 2 Infrared spectral data

\begin{tabular}{clcrl} 
& \multicolumn{4}{c}{ Wavenumber $\left(\mathrm{cm}^{-1}\right)$} \\
\cline { 2 - 5 } Complex & \multicolumn{1}{c}{$\nu_{4}$} & \multicolumn{1}{c}{$\nu_{1}$} & \multicolumn{1}{c}{$\nu_{3}$} \\
\hline$[1]$ & $664(\mathrm{~m}), 724(\mathrm{~m})$ & $861(\mathrm{~s})$ & $1062(\mathrm{w})$ & $1333(\mathrm{vs}), 1373(\mathrm{vs})$ \\
& $735(\mathrm{w})$ & & & $1400(\mathrm{vs}, \mathrm{sh}), 1446(\mathrm{vs})$ \\
{$[2]$} & $626(\mathrm{~m}), 719(\mathrm{~m})$ & $851(\mathrm{~s})$ & $1057(\mathrm{w})$ & $1304(\mathrm{vs}), 1324(\mathrm{vs}, \mathrm{sh})$ \\
& $742(\mathrm{w})$ & & $1079(\mathrm{~m})$ & $1366(\mathrm{vs}), 1400(\mathrm{vs}, \mathrm{sh})$ \\
& & & & $1461(\mathrm{vs}), 1527(\mathrm{vs})$ \\
{$[3]$} & $628(\mathrm{~m}), 721(\mathrm{~m})$ & $853(\mathrm{~s})$ & $1056(\mathrm{w})$ & $1308(\mathrm{vs}), 1323(\mathrm{vs}, \mathrm{sh})$ \\
& $743(\mathrm{w})$ & & $1083(\mathrm{~m})$ & $1369(\mathrm{vs}), 1400(\mathrm{vs}, \mathrm{sh})$ \\
& & & & $1462(\mathrm{vs}), 1528(\mathrm{vs})$ \\
& $647(\mathrm{~m}), 722(\mathrm{~m})$ & $852(\mathrm{~s})$ & $1062(\mathrm{w})$ & $1317(\mathrm{vs}), 1362(\mathrm{vs})$ \\
& $747(\mathrm{w})$ & & $1087(\mathrm{~m})$ & $1472(\mathrm{vs}), 1522(\mathrm{vs})$
\end{tabular}

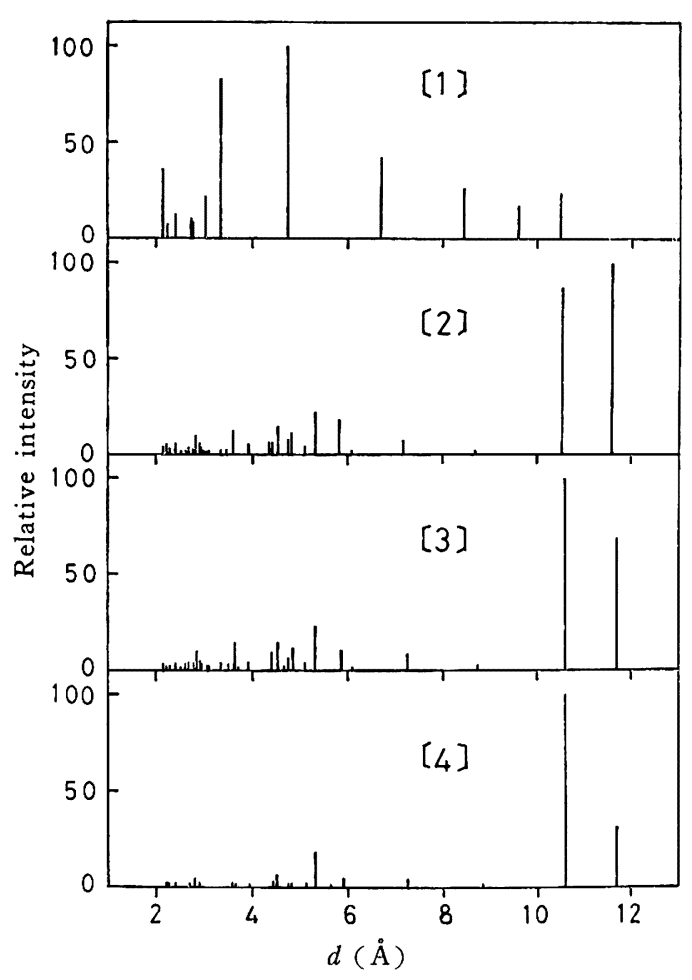

Fig. 1 X-ray diffraction patterns

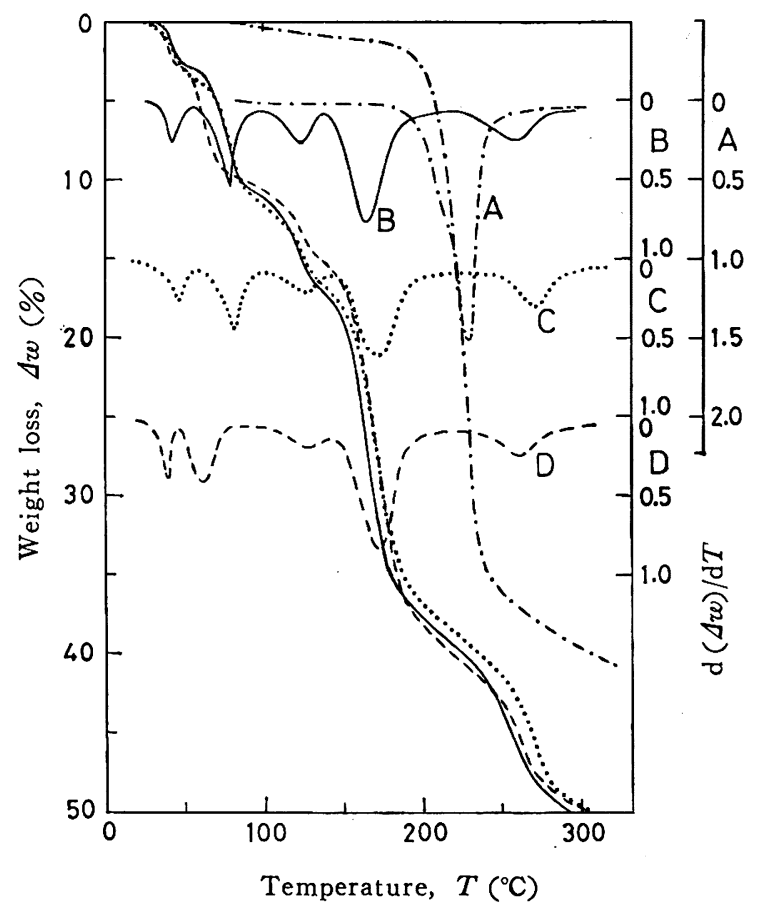

Fig. 2 TG and DTG curves $-.-:[1], \longrightarrow:[2], \cdots \cdots:[3],---[4]$ Heating rate : ca. $0.7^{\circ} \mathrm{C} \cdot \mathrm{min}^{-1}$ 
かなり大きいことより，今回得られた複錯塩では，希土類金属と カルボナト配位子との結合は，かなりイオン性が高いものと思わ れる。さらに，一般に希土類金属イオンの配位数が 6 よりも大き いことから，水分子の配位やカルボナト配位子の希土類金属イオ ン間の橋かけの可能性す十分に考えられる。このような結晶のス ペクトル解析には, Facter group analysisなどによる検討が必要 であるが，結晶学的データを得るまでにはいたっていない。

\section{3 熱 分 解}

各複錯塩の TG および DTG 曲線を図 2 に示す。〔1〕の TG 曲線が他の三つの複錯塩とかなり異なって技り，粉末 X線回折パ ターンの差異とも非常によく対応していることがわかる。また, 〔1]の $200^{\circ} \mathrm{C}$ での, 他の三つの複錯塩の 50,85 および $130^{\circ} \mathrm{C}$ での重量減少率（\%) を表 3 に示す。発生ガス成分を質量分析計 で調べた結果，〔1〕では約 $200^{\circ} \mathrm{C}$ 以下で，〔2〕，〔3〕および [4]では約 $150^{\circ} \mathrm{C}$ 以下で水分子のみが，それら以上の温度では アンモニアおよび二酸化炭素が検出された。これらの結果と表 3 の重量減少率から、それぞれの複錯塩の水の脱離はつぎのよらに 段階的に進行するものと考えられる。

[1] $\underset{E_{3} \neq}{\stackrel{-\mathrm{H}_{2} \mathrm{O}}{\longrightarrow}}$ anhydrate

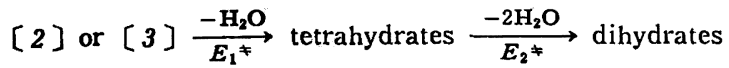

$$
\stackrel{-2 \mathrm{H}_{2} \mathrm{O}}{\underset{E_{3} \neq}{\longrightarrow}} \text { anhydrate }
$$

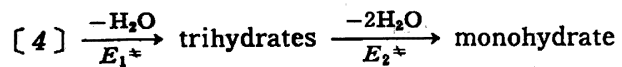

$$
\underset{E_{3} \neq}{\stackrel{-\mathrm{H}_{2} \mathrm{O}}{\longrightarrow}} \text { anhydrate }
$$

ここで, 〔1]の脱水は〔2],〔3]および〔4]の第三段階目の 脱水過程に相当すると考学るのが妥当であると思われる。約 0.7 $\sim 10.5^{\circ} \mathrm{C} / \mathrm{min}^{-1}$ の種々の昇温速度で TG 曲線を測定した結果, 昇温速度の增大とともに TG 曲線が高温側に移行することがわ かったので，既報()と同様に Doyle の方法"゙および Wiedemann

Table 3 Observed weight losses (\%)

\begin{tabular}{ccccc} 
& \multicolumn{4}{c}{ Weight loss(\%) at } \\
\cline { 2 - 5 } Complex & $50^{\circ} \mathrm{C}$ & $85^{\circ} \mathrm{C}$ & $130^{\circ} \mathrm{C}$ & $200^{\circ} \mathrm{C}$ \\
\hline$[1]$ & & & & 3.00 \\
{$[2]$} & 2.71 & 10.02 & 16.00 & \\
{$[3]$} & 3.03 & 10.10 & 15.80 & \\
{$[4]$} & 3.00 & 9.95 & 14.35 &
\end{tabular}

Table 4 Activation energy

\begin{tabular}{cccr} 
& \multicolumn{3}{c}{$\left(\mathrm{KJ} \mathrm{mol}^{-1}\right)$} \\
\cline { 2 - 4 } & $E_{1} *$ & \multicolumn{1}{c}{$E_{2}{ }^{*}$} & \multicolumn{1}{c}{$E_{3}{ }^{*}$} \\
\hline$[1]$ & & & $79.3 \pm 6.5$ \\
{$[2]$} & $167.8 \pm 29.7$ & $205.5 \pm 16.4$ & $107.8 \pm 5.8$ \\
{$[3]$} & $182.4 \pm 32.2$ & $203.2 \pm 9.9$ & $128.1 \pm 7.3$ \\
{$[4]$} & $196.6 \pm 31.4$ & $238.5 \pm 8.7$ & $104.6 \pm 7.8$
\end{tabular}

7) C. D. Doyle, J. Appl. Polym. Sci., 5, 285(1961); C. D. Doyle, "Techniques and Methods of Polymer Evaluation", ed. by P.E. Slade, Jr., L. T. Jenkins, Marcel Dekker (1966) p. 113 ; 神戸博太郎, “熱分析”, 誮談社 (1975) p. 96.

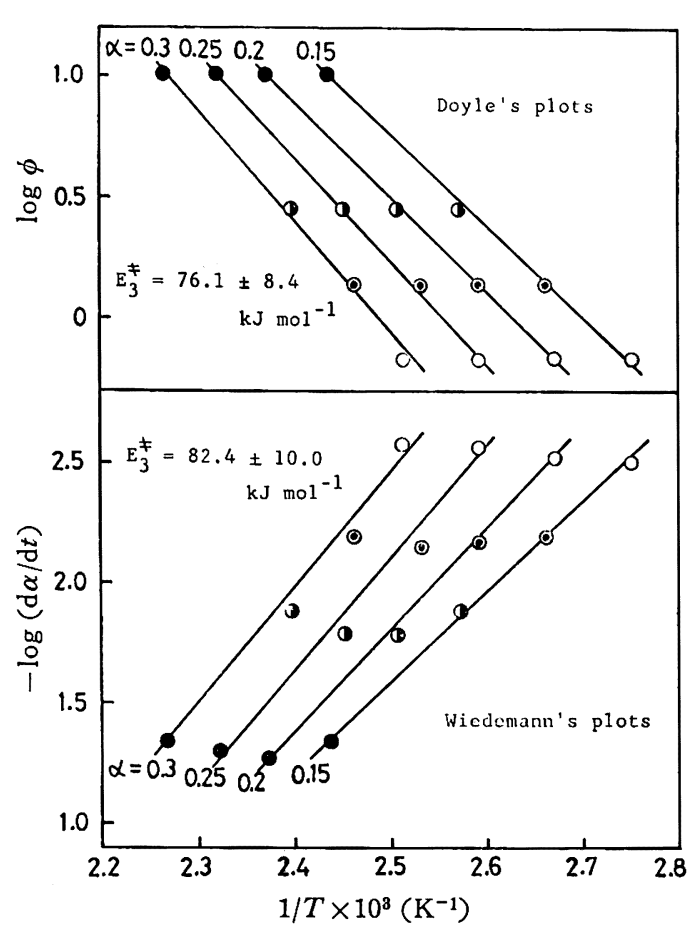

Fig. 3 The Doyle's and Wiedemann's plots for double complex salt [1]

Heating rate $\left(\phi /{ }^{\circ} \mathrm{C} \cdot \mathrm{min}^{-1}\right)$ :

$0.67 ; \bigcirc, 1.40 ; \odot, 2.84 ; \bigcirc, 10.33$;

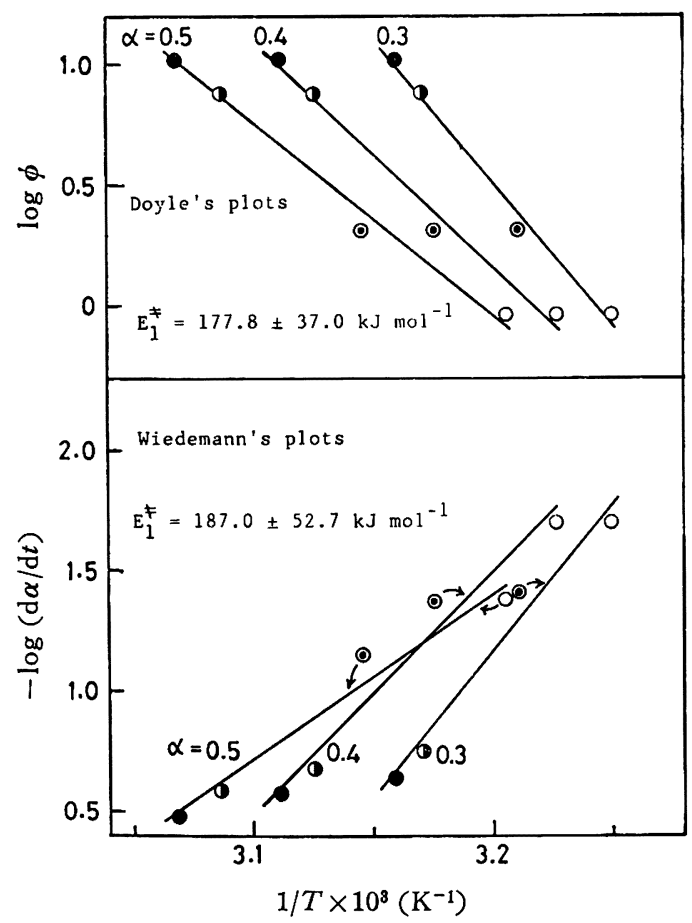

Fig. 4 The Doyle's and Wiedemann's plots for the first dehydration step of double complex salt [3]

Heating rate $\left(\phi /{ }^{\circ} \mathrm{C} \cdot \mathrm{min}^{-1}\right)$ :

$0.91 ; \bigcirc, 2.04 ; \odot, 7.52 ; \bigcirc, 10.54 ;$ 


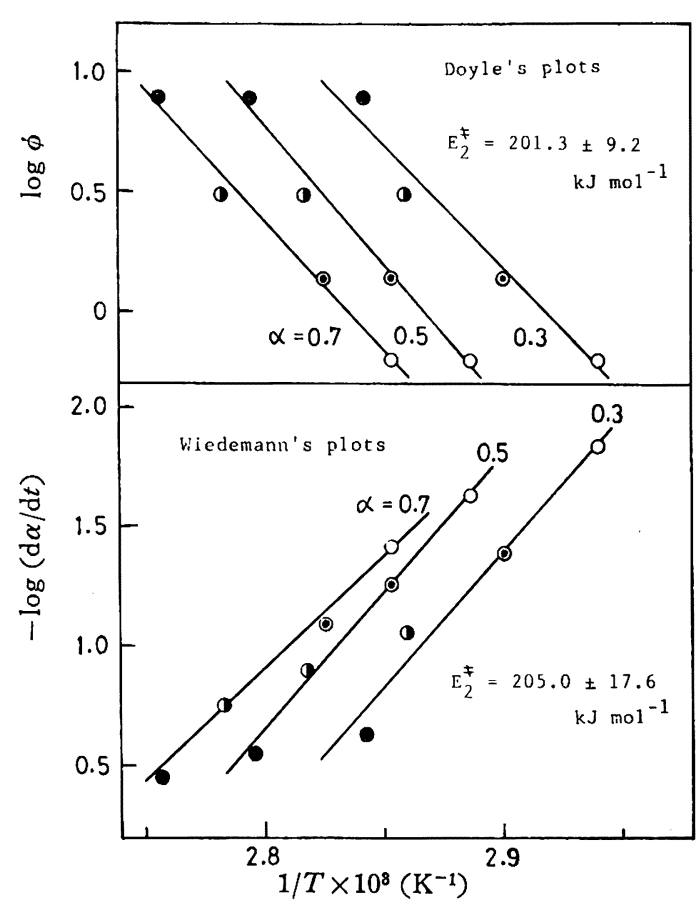

Fig. 5 The Doyle's and Wiedemann's plots for the second dehydration step of double complex salt [3]

Haeting rate $\left(\phi /{ }^{\circ} \mathrm{C} / \mathrm{min}^{-1}\right)$ :

$0.63 ; \bigcirc, 1.39 ; \odot, 3.09 ; \bigcirc, 8.00 ;$

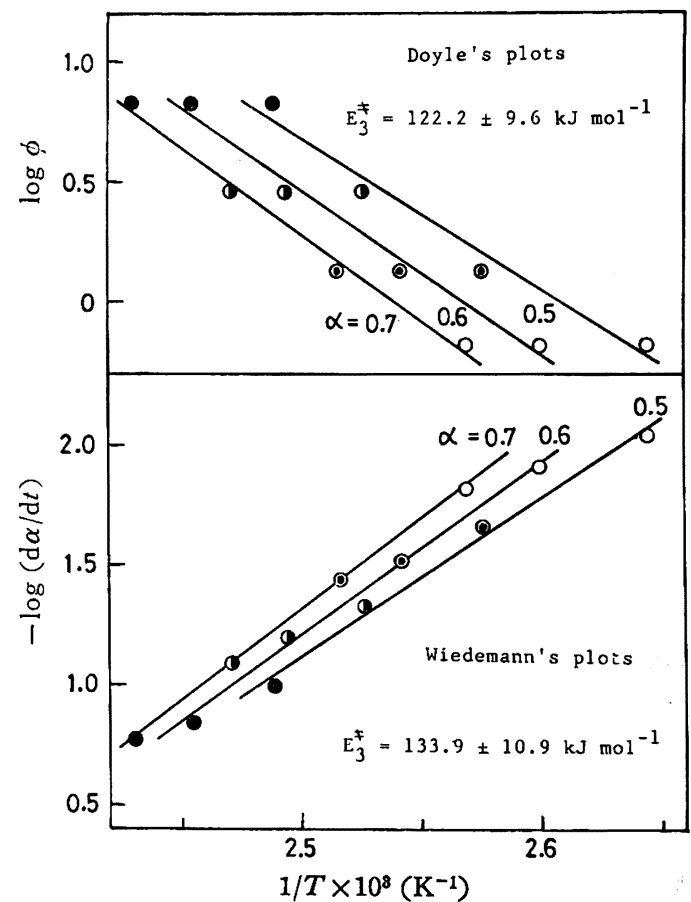

Fig. 6 The Doyle's and Wiedemann's plots for the third dehydration step of double complex salt [3]

Heating rate $\left(\phi /{ }^{\circ} \mathrm{C} \cdot \mathrm{min}^{-1}\right)$ :

$0.66 ; \bigcirc, 1.36 ; \odot, 2.85 ; \bigcirc, 6.72 ;$

0.7 (第二段階) および $0.5 \sim 0.7$ (第三段階) の領域を用いた。 例として〔1]および〔3]の場合のプロットをそれぞれ図 3 お よび図 4〜6に示す。二つの方法によって得られた活性化ェネル ギーの平均值を標準偏差とともに示す。〔2], [3]および〔4] のいずれも第三段階目の脱水反応の值がもっとも小さい。

終りに, 本研究を行ならにあたり, 多大な御助言を睗りました 愛媛大学工学部石森富太郎教授飞感謝致します。

（1983 年 4 月, 日本化学会第 47 春季年会 (一部) 発表) Applied Spectroscopy, Pittsburgh, PA, February 21, (1966).

\author{
Infrared Spectra and Thermal Decomposition of Double Complex Salts, \\ $\left[\mathrm{Co}\left(\mathrm{NH}_{3}\right)_{6}\right]\left[\mathrm{Ln}\left(\mathrm{CO}_{3}\right)_{3}\right] \cdot \boldsymbol{n} \mathrm{H}_{2} \mathrm{O}(\mathrm{Ln}=\mathrm{La}, \mathrm{Sm}, \mathrm{Gd}, \mathrm{Ho})$ \\ Masatomi SAKAMOTO \\ Department of Industrial Chemistry, Faculty of Engineering, Ehime University; \\ Bunkyo-cho, Matsuyama-shi 790 Japan
}

Studies on the infrared spectra and thermal properties of $\left.\left[\mathrm{Co}\left(\mathrm{NH}_{3}\right)_{6}\right]\left[\mathrm{La}\left(\mathrm{CO}_{3}\right)_{3}\right] \cdot \mathrm{H}_{2} \mathrm{O}\right][1]$, $\left[\mathrm{Co}\left(\mathrm{NH}_{3}\right)_{6}\right]\left[\mathrm{Sm}\left(\mathrm{CO}_{3}\right)_{3}\right] \cdot 5 \mathrm{H}_{2} \mathrm{O} \quad[2], \quad\left[\mathrm{Co}\left(\mathrm{HN}_{3}\right)_{6}\right]\left[\mathrm{Gd}\left(\mathrm{CO}_{3}\right)_{3}\right] \cdot 5 \mathrm{H}_{2} \mathrm{O} \quad[3], \quad\left[\mathrm{Co}\left(\mathrm{NH}_{3}\right)_{6}\right][\mathrm{Ho}$ $\left.\left(\mathrm{CO}_{3}\right)_{3}\right] \cdot 4 \mathrm{H}_{2} \mathrm{O}[4]$ were undertaken. The infrared spectra of carbonato ligands of these double complex salts were much more complicated than those of free carbonate ion and coordinating carbonates like those in $\left[\mathrm{Co}\left(\mathrm{NH}_{3}\right)_{5} \mathrm{CO}_{3}\right] \mathrm{Br}$ and $\left[\mathrm{Co}\left(\mathrm{NH}_{3}\right)_{4} \mathrm{CO}_{3}\right] \mathrm{Cl}$, etc. [2], [3] and [4] show the absorptions attributable to $\nu_{3}$ vibrational mode beyond $1500 \mathrm{~cm}^{-1}$, whereas [1] does not. Furthermore, dehydration of [2], [3] and [4] were found to occur in three stages. Values of activation energy in these dehydration processes were estimated using modified Doyle's and Wiedemann's methods. 